\title{
Novidades taxonômicas em Ericaceae para o Brasil: uma nova espécie para Gaylussacia e uma combinação nova para Gaultheria
}

Taxonomic novelties in Ericaceae for Brazil: a new species of Gaylussacia and a new combination for Gaultheria

Gerson Oliveira Romão ${ }^{1}$ \& Luiza Sumiko Kinoshita ${ }^{2}$

\begin{abstract}
Resumo
Como resultado do levantamento taxonômico das espécies de Gaylussacia Kunth, descreve-se uma nova espécie, Gaylussacia paranaensis G.O. Romão \& Kinoshita. É também proposta para Gaultheria L. uma nova combinação, Gaultheria corvensis (R.R. Silva \& Cervi) G.O. Romão \& Kinoshita, esta baseada em Gaylussacia corvensis. Ambas as espécies estão restritas à Região Sul do Brasil, sendo que Gaylussacia paranaensis ocorre no município de Antonina, Paraná, e caracteriza-se por apresentar folhas elípticas com margem regularmente serrilhada a serreada e brácteas com glândula apical-espessa e Gaultheria corvensis ocorre na Serra do Corvo Branco, Município de Grão Pará, Santa Catarina.

Palavras-chave: Paraná, Santa Catarina, taxonomia.
\end{abstract}

\begin{abstract}
As a result of a taxonomic survey of the Gaylussacia Kunth, a new species is described, Gaylussacia paranaensis G.O. Romão \& Kinoshita. And a new combination for Gaultheria L., Gaultheria corvensis (R.R. Silva \& Cervi) G.O. Romão \& Kinoshita is proposed, based on Gaylussacia corvensis. The two species are restricted to Southern Brazil. Gaylussacia paranaensis is found in Antonina municipality, Paraná state, and characterized by elliptic leaves, margin regularly serrulate to serrate and apical gland on the bract, while Gaultheria corvensis is found in Serra do Corvo Branco, Grão Pará municipality, Santa Catarina state.

Key words: Paraná, Santa Catarina, taxonomy.
\end{abstract}

\section{Introdução}

Ericaceae Juss. possui distribuição cosmopolita e ocorre principalmente nas regiões temperadas e subtropicais, abrangendo cerca de 160 gêneros e 4.500 espécies (Luteyn et al. 1995). No Brasil, a família está representada por 12 gêneros, dentre esses Gaultheria e Gaylussacia, e aproximadamente 90 espécies (Kinoshita-Gouvêa 1979).

Os representantes desta família variam desde subarbustos até árvores, algumas vezes lianas, epífitas ou ervas aclorofiladas e micotróficas. Apresentam tricomas unicelulares ou multicelulares, simples, dendríticos, glandulares ou lepidotos, às vezes com glândulas. As folhas são simples, alternas a opostas ou verticiladas, geralmente coriáceas. As flores são vistosas, sépalas e pétalas 37, livres entre si ou conadas integralmente ou apenas na base, podendo a corola ser urceolada até campanulada ou infundibuliforme. Os estames são geralmente em número de 10 , com anteras poricidas, e o ovário súpero ou ínfero. Os frutos são do tipo baga, drupóide ou cápsula (Meisner 1863; Judd et al. 1999).

A partir de um levantamento taxonômico das espécies de Gaylussacia, propõe-se uma nova espécie, Gaylussacia paranaensis G.O. Romão \& Kinoshita, e uma nova combinação, Gaultheria corvensis (R.R. Silva \& Cervi) G.O. Romão \& Kinoshita. 


\section{Material e Métodos}

Foram analisados os materiais-tipo das 51 espécies de Gaylussacia, segundo Sleumer (1967), Kinoshita-Gouvêa (1981), Kinoshita (1995) e Silva \& Cervi (1999, 2003), bem como materiais obtidos em expedições de campo realizadas nas regiões serranas no Sul do Brasil, ao final do ano de 2006.

\section{Resultados e Discussão}

Gaylussacia paranaensis G.O. Romão \& Kinoshita, sp. nov. Tipo: BRASIL. PARANÁ: Antonina, Usina Hidrelétrica Parigot de Souza, subida da cota 800 , 12.I.2006, fl. e fr., O.S. Ribas \& J.M. Silva 7124 (holótipo MBM!).

Fig. 1

Frutex 1,5-2 $m$ altus. Trichoma simplex, album; rami glabri. Folia 2,6-5,5 cm longa, 1$1,8 \mathrm{~cm}$ lata, chartaceus; lamina elliptica, margine undique serratus vel serrulatus, glabra vel sparse puberula usque pubescens costa. Flores 4-9; rhachis 2,4-9,9 cm longis, glabris; bractea foliacea, 8-17 mm longa, glandula apicalis crassaelongata; bracteolae lineari-filiformes. Calyx ciliatus; corolla campanulata usque tubulosacampanulata, 4-6 mm longa, alba, glabra. Fructus costatus, ruber. Haec species proxime affinis est Gaylussacia angulata Gardner, a qua folia maiora, 1-1,8 cm lata, laminae ellipticae, rhachis glabris, bractea foliace a maiora, 8-17 mm longa et glandula apicalis crassa-elongata praecipue differt.

Arbusto, 1,5-2 m alt., base ereta, copa fastigiada. Ramos geralmente lisos, glabros, râmulo esparsamente foliado, estriado-angulado, ramos adultos geralmente desfoliados. Tricomas simples, alvos, às vezes presentes nas folhas, brácteas ou cálice Folhas 2,6-5,5×1-1,8 cm, cartáceas, discolores; limbo estreitamente elíptico, ápice agudo, mucronulado, com glândula apical espesso-alongada, base aguda a atenuada, margem inteiramente serreada ou serrilhada, plana, face superior glabra ou esparsamente pubérula a pubescente apenas na nervura central, face inferior glabra, geralmente com glândulas capitado-clavadas, rubras a amareladas, esparsamente dispostas por todo o limbo em ambas as faces, nervuras levemente proeminentes; pecíolo 2-4 mm compr., glabro ou esparsamente pubescente. Racemos axilares subapicais, paucifloros, 4-9 flores; ráquis 2,4-9,9 cm compr., glabra, geralmente com glândulas capitadas; bráctea floral foliácea, 8-17 mm compr., estreitamente elíptica a lanceolada, glabra ou apenas ciliada, raro pubescente na nervura, geralmente com glândulas capitado-amareladas e glândula apical espesso-alongada; bractéolas 4-6 mm compr., linearfiliformes, inseridas da base até o meio do pedicelo. Flores com pedicelo 1-7 mm compr.; hipanto glabro; cálice 0,5-1 mm compr., apenas ciliado, lobos largamente triangulares; corola campanulada a tubuloso-campanulada, raramente cilíndrica, 4-6 mm compr., branca, glabra em ambas as faces; estames 10 , 2,5-3 mm compr., filetes densamente tomentosos; disco nectarífero glabro; ovário ínfero; estilete 3-4 mm compr., glabro, raramente tomentoso na base. Nuculânio 2-4 mm diâm., depresso-subgloboso, costado, avermelhado, glabro.

Material examinado: BRASIL. PARANÁ: Antonina, 800 m, 10.I.1994, fl. e fr., G. Hatschbach \& E. Barbosa 59795 (parátipo MBM).

Até o momento coletada somente no estado do Paraná, no município de Antonina, nas proximidades da Serra da Graciosa, em altitudes em torno de $800 \mathrm{~m}$.

Espécie encontrada em campos de altitude próximos à Serra do Mar; floresce e frutifica em janeiro.

Essa espécie relaciona-se com Gaylussacia angulata Gardner, por apresentar folhas com a margem regularmente serrilhada a serreada, mas difere quanto ao tamanho e formato das folhas, glândula apical nas brácteas florais e distribuição geográfica. Enquanto G. paranaensis possui folhas 2,6-5,5×1-1,8 cm, elípticas, brácteas florais com glândula-apical espessa e ocorre somente na região de Antonina, no estado do Paraná, G. angulata apresenta folhas menores, 1,5-3,3 × 0,5-1,1 cm, obovadas a oblanceoladas, ausência de glândula apical nas brácteas, além de estar restrita à Serra dos Órgãos e à região de Santa Maria Madalena, estado do Rio de Janeiro.

Gaylussacia paranaensis foi assim designada por ocorrer apenas em área restrita no estado do Paraná.

Gaultheria corvensis (R.R. Silva \& Cervi) G.O. Romão \& Kinoshita, comb. nov. Gaylussacia corvensis R.R. Silva \& Cervi, Sellowia 53: 23. 2003. Tipo: Brasil. Santa CATARINA: Grão Pará, Serra do Corvo Branco, 10.XII.2000, fl., G. Hatschbach, A.C. Cervi \& E.Barbosa 71783 (holótipo MBM!; isótipos HBR, UPCB!).

Fig. 2

Subarbusto, 20-50 cm alt., base procumbente, bastante ramificado no ápice. Tricomas simples, alvos, às vezes presentes nos ramos, brácteas e pedicelo. Ramo rugoso, geralmente descamante, desfoliado nas partes adultas, râmulos angulosos, glabros a esparsamente pubescentes, geralmente com glândulas enegrecidas. Folhas $1-3,5 \times 0,2-$ 

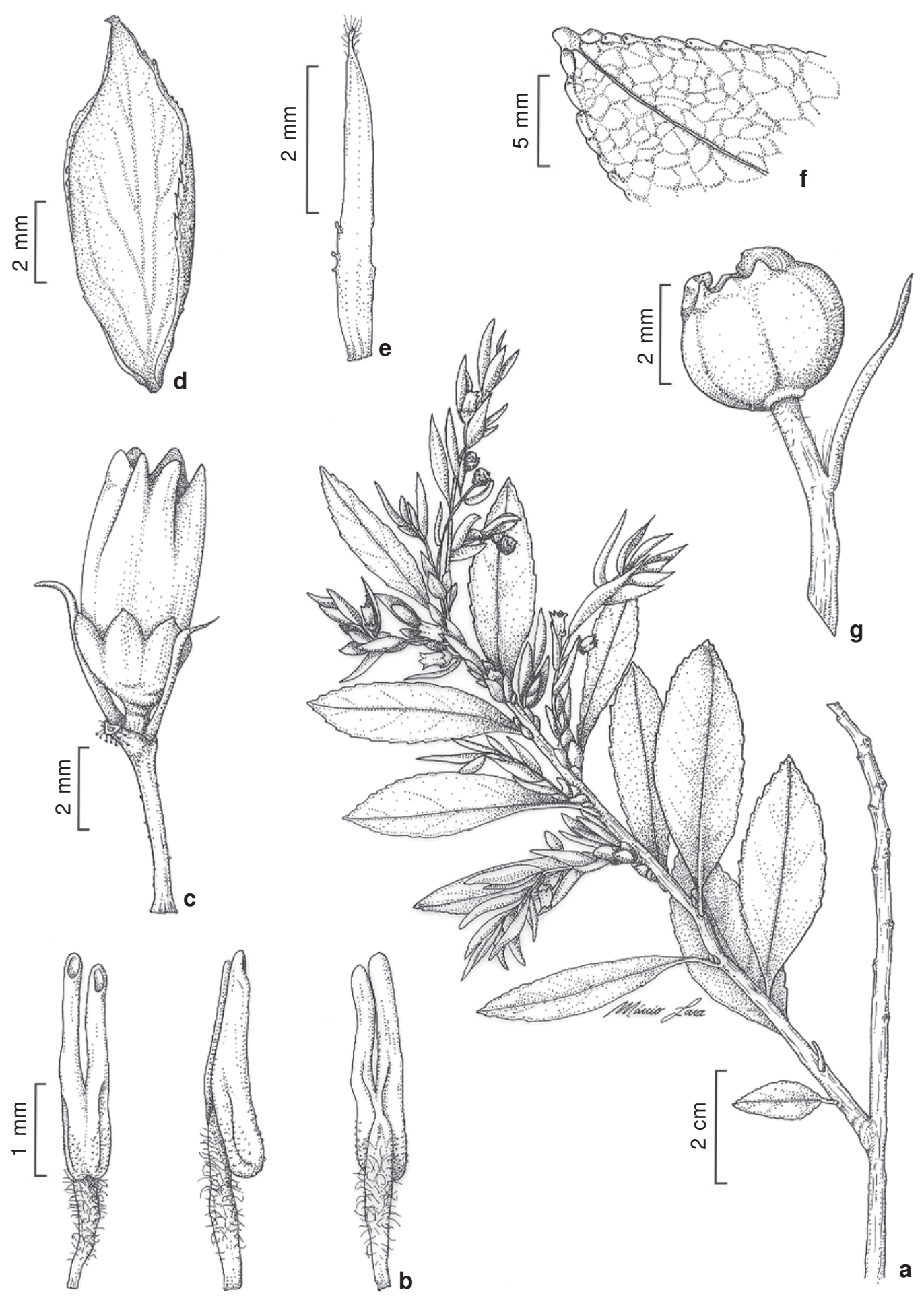

Figura 1 - Gaylussacia paranaensis G.O. Romão \& Kinoshita - a. ramo florífero; b. estames em vista frontal, lateral e dorsal; c. flor; d. bráctea; e. bractéola; f. detalhe da margem da folha; g. fruto jovem (Ribas \& Silva 7124).

Figure 1 - Gaylussacia paranaensis G.O. Romão \& Kinoshita - a. flowering branch; b. stamen in front, lateral and behind view; c. flower; d. bract; e. bracteole; f. margin of the leaf in detail; g. young fruit (Ribas \& Silva 7124). 

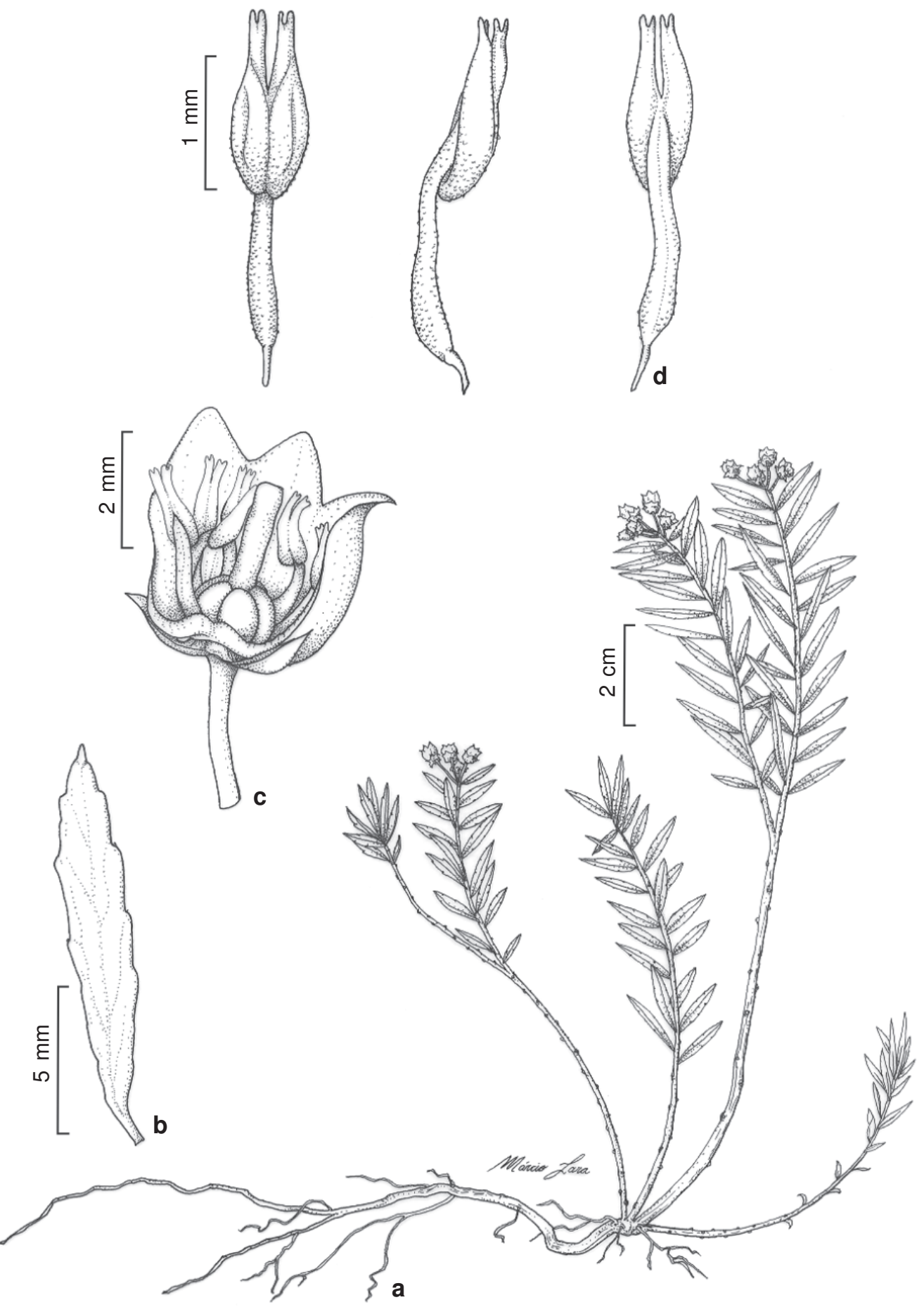

Figura 2 - Gaultheria corvensis (R.R. Silva \& Cervi) G.O. Romão \& Kinoshita - a. ramo com flores; b. folha; c. secção da flor evidenciando estames e gineceu; d. estames em vista frontal, lateral e dorsal (Romão et al. 1809).

Figure 2 - Gaultheria corvensis (R.R. Silva \& Cervi) G.O. Romão \& Kinoshita - a. stem with flowers; b. leaf; c. flower longitudinal section, showing stamens and gynoecium d. stamen in front, lateral and behind view (Romão et al. 1809). 
0,6 cm, adensadas nos ápices, cartáceas; limbo linear a lanceolado, ápice agudo a atenuado, glândula apical-espessa, base aguda, margem inteiramente serrilhada, plana, com glândulas clavadas no ápice dos dentes, ambas as faces glabras, comumente com glândulas pontuadas esparsamente dispostas na face inferior; nervuras impressas na face superior, levemente proeminente na inferior; pecíolo geralmente enegrecido, 1-3 mm compr., glabro. Inflorescências em pseudoracemos geralmente terminais, não bracteados na base, 2-13 flores; brácteas florais e bractéolas 2, rômbico-deltóides, conduplicadas, inseridas na base do pedicelo, esparsamente ciliadas; ráquis 4-18(-25) mm compr., esparsa a subdensamente pubescente. Flores com pedicelo 3-5 mm compr., pubescente; cálice 1-2 mm compr., glabro, lobos deltóides; corola cilíndrica a subcampanulada, raramente tubuloso-urceolada, branca, 2,5-4 (-5) mm compr., glabra, lobos deltóides; estames 10,2-4 mm compr., filetes com base alargada, densamente pubérulos; ovário globoso, 1-1,5 mm diâm., glabro, estilete glabro a pubérulo. Cápsula castanho-escura, 2-3 mm diâm., globosa, glabra.

Material examinado: BRASIL. SANTA CATARINA: Grão Pará, Serra do Corvo Branco, a 800 m após o cume em direção a Grão Pará, 1.XI.2006, fl. e fr., G.O. Romão et al. 1808, 1809, 1810, 1811, 1812, 1813, 1814 (ESA, $\mathrm{G}, \mathrm{K}, \mathrm{M}, \mathrm{RB}, \mathrm{SPF}, \mathrm{UEC})$.

Ocorre somente no estado de Santa Catarina, sendo endêmica da Serra do Corvo Branco, em altitude de $1.450 \mathrm{~m}$.

Está presente em paredões rochosos de altitude, bastante úmidos e sob intensa influência de neblina. Floresce e frutifica nos meses de novembro e dezembro.

Gaultheria corvensis pertence à seção Monoanthemona ser. Itatiaiae, caracterizada pela corola cilíndrico-campanulada. Primeiramente essa espécie foi descrita para o gênero Gaylussacia por Silva \& Cervi (2003). Contudo, apresenta ovário súpero, filetes retos e anteras bidenteadas com tecas não longamente-tubulosas, características marcantes em Gaultheria.

De acordo com Kinoshita-Gouvêa (1979), Gaultheria bradeana juntamente com G. myrtilloides, G. ulei, G. sleumeriana e G. itatiaiae pertencem ao grupo das Gaultheria “pernetóides”, isto é, de folhas semelhantes às do gênero Pernettya. Gaultheria corvensis também apresenta folhas semelhantes às de Pernettya e, portanto, aproximase bastante desse grupo "pernetóide". Como complemento à chave para as espécies apresentada na Flora Neotropica por Luteyn (1995), G. corvensis está próxima de G. ulei e G. itatiaiae, que apresentam folhas coriáceas, ovaladas a oblanceoladas, de 0,4-1,4(-2) cm de largura e ovário piloso, ao contrário de G. corvensis, que possui folhas cartáceas, lineares a lanceoladas, mais estreitas (0,2-0,6 cm larg.) e ovário glabro.

\section{Agradecimentos}

Os nossos sinceros agradecimentos ao Prof. Vinicius Castro Souza, as sugestões; ao Sr. Márcio Stefanelli Lara, as ilustrações, e à Fundação de Amparo à Pesquisa do Estado de São Paulo (FAPESP) o apoio financeiro (processo n ${ }^{\circ}-03 / 13061-6$ ).

\section{Referências}

Judd, W.S.; Campbell, C.S.; Kellogg, E.A. \& Stevens, P.F. 1999. Plant systematics, a phylogenetic approach. Sinauer Associates Inc., Sunderland. 469p.

Kinoshita-Gouvêa, L.S. 1979. Estudos taxonômicos e fitogeográficos da família Ericaceae no Brasil. Tese de Doutorado. Universidade de São Paulo, São Paulo. 417p.

Kinoshita-Gouvêa, L.S. 1981. Novas espécies de Ericaceae para o Brasil: Gaultheria sleumeriana, Leucothoe chapadensis e Gaylussacia setosa. Revista Brasileira de Botânica 4: 125-130.

Kinoshita, L.S. 1995. Ericaceae. In: Stannard, B.L.; Harvey, Y.B. \& Harley, R.M. (eds.). Flora of the Pico das Almas, Chapada Diamantina-Bahia, Brazil. Royal Botanical Gardens, Kew. Pp. 291-296.

Luteyn, J.L.; Judd, W.S.; Clemants, S.E.; Diggs, G.M.; Sørensen, P.D.; Dorr, L.J.; Wallace, G.D. \& Stevens, P.F. 1995. Ericaceae - part. II. The superior ovaried genera. Flora Neotropica. Vol. 66. The New York Botanical Garden, New York. 561p.

Meisner, C.F. 1863. Ericaceae. In: Martius, C.F.P (ed). Flora brasiliensis. Vol 7. Pp. 118-182.

Silva, R.R. \& Cervi, A.C. 1999. Gaylussacia novae (Ericaceae) Brasilia australi nuper inventae. Fontqueria 54: 1-6.

Silva, R.R. \& Cervi, A.C. 2003. Gaylussacia corvensis R.R. Silva \& Cervi (Ericaceae) ex Brasilia australi nova species inventa. Sellowia 53: 23-27.

Sleumer, H. 1967. Die gattung Gaylussacia H.B.K. Botanische Jahrburcher Systematik 86: 309-384. 